\title{
Valuing Ecosystem Services: Oysters, Denitrification, and Nutrient Trading Programs
}

\author{
GS DePiper
}

DW Lipton

RN Lipcius

Virginia Institute of Marine Science, rom@vims.edu

Follow this and additional works at: https://scholarworks.wm.edu/vimsarticles

Part of the Marine Biology Commons

\section{Recommended Citation}

DePiper, GS; Lipton, DW; and Lipcius, RN, "Valuing Ecosystem Services: Oysters, Denitrification, and Nutrient Trading Programs" (2017). VIMS Articles. 1853.

https://scholarworks.wm.edu/vimsarticles/1853

This Article is brought to you for free and open access by the Virginia Institute of Marine Science at W\&M ScholarWorks. It has been accepted for inclusion in VIMS Articles by an authorized administrator of W\&M ScholarWorks. For more information, please contact scholarworks@wm.edu. 


\title{
Valuing Ecosystem Services: Oysters, Denitrification, and Nutrient Trading Programs
}

Geret S. DePiper and Douglas W. Lipton, NOAA Fisheries; Romuald N. Lipcius, College of William \& Mary

\begin{abstract}
A B S TRACT
As part of their strategy to meet total maximum daily load restrictions in the Chesapeake Bay, managers have developed nutrient trading markets to curb nitrogen and phosphorus flows into the estuarine system. Historically, nutrient trading programs have been restricted to credits between point sources or for agricultural mitigation technologies, such as the planting of cover crops. However, the denitrification and nutrient sequestration associated with oyster reefs has recently been a topic of much biological research. We investigate the role that nutrient credits for ecosystem services provided by restored oyster reefs can play in optimally managing oyster reef complexes by developing a coupled bioeconomic model of oyster reef growth and harvest. Our findings suggest that, along with harvest, the regulating services of denitrification and nutrient sequestration lead to positive net benefits in a majority of scenarios analyzed, although local environmental conditions play a prominent role in the ultimate outcomes.
\end{abstract}

Key words: Oyster reef, ecosystem services, denitrification, nutrient sequestration.

JEL Codes: Q22, Q57, Q53.

\section{INTRODUCTION}

Restoring oyster reefs is a primary goal of large-scale coastal ecosystem restoration programs, such as in the Chesapeake Bay (Chesapeake Bay Program 2014a) and Gulf of Mexico (Brown et al. 2014). Oysters are dominant ecosystem engineers ${ }^{1}$ that provide diverse benefits to marine and estuarine species, including food, refuge from predators, and buffers from physical stress (Luckenbach, Mann, and Wesson 1995). Given that oyster reef ecosystem services are a public good, restoration has mostly been conducted as a public enterprise funded by taxpayer dollars, and thus, may be severely constrained by static or declining state and federal budgets.

A potential alternative mechanism to fund oyster restoration in the Chesapeake Bay (the Bay) arose in December 2010 when the US Environmental Protection Agency (EPA) instituted total maximum daily load (TMDL) levels for nitrogen and phosphorus in the Bay to combat their degrading effects on the environment (Environmental Protection Agency 2011). Nitrogen and

Geret S. DePiper is an economist, NOAA Fisheries, 166 Water Street, MB 19, Woods Hole, MA 02543 USA (email: geret.depiper@noaa.gov). Douglas W. Lipton is senior scientist for economics, NOAA Fisheries, 1315 East-West Highway, Silver Spring, MD 20910 USA (email: douglas.lipton@noaa.gov). Romuald N. Lipcius is a professor of marine science, Virginia Institute of Marine Science, College of William \& Mary, PO Box 1346, Gloucester Point, VA 23062 USA (email: rom@vims.edu).

We thank participants at a Woods Hole Oceanographic Institution Biology Department Seminar, particularly Julie Kellner, for helpful suggestions in the link between filtration rates and denitrification. R. N. Lipcius received grant funding from the US National Science Foundation \#DMS-1313093 and acknowledges intellectual discussions with Junping Shi and Leah Shaw.

1. The role that organisms play in the creation and maintenance of habitat (Jones, Lawton, and Shachak 1994).

Received August 24, 2015; Accepted June 22, 2016; Published online November 3, 2016. http://dx.doi.org/10.1086/688976

Marine Resource Economics, volume 32, number 1. (c) 2016 MRE Foundation, Inc. All rights reserved. 0738-1360/2016/3201-0001\$10.00 
phosphorus are the two major nutrient pollutants of concern in the Chesapeake Bay in terms of natural resource (Boesch, Brinsfield, and Magnien 2001; Hagy et al. 2004) and human health (Magnien 2001; Birch et al. 2011). The TMDL regulations apply to seven jurisdictions across the Bay watershed: Delaware, Maryland, New York, Pennsylvania, Virginia, Washington, DC, and West Virginia. Each jurisdiction has developed watershed implementation plans to comply with TMDL regulations. Pennsylvania, Maryland, Virginia, and West Virginia have instituted nutrient trading programs as part of their state plans (Branosky, Jones, and Selman 2011). Between 2011 and 2014, credits covering 1,293,916 lbs. of nitrogen were traded in these programs (Virginia Department of Environmental Quality 2016; Markit Financial Information Services 2016). Further, a Trading and Offsets Workgroup with members from all seven jurisdictions and relevant federal agencies meets monthly to standardize the development and trading of nutrient credits across jurisdictions (Chesapeake Bay Program 2014b). These nutrient trading programs have mostly been designed to generate credits through land-based mitigation activities, such as cover-crop plantings and development of farm-based nutrient management plans (Branosky, Jones, and Selman 2011). However, there is increasing interest in determining whether credits for trading should also be awarded for the sequestration and denitrification services provided by oyster populations, given their historical role in mediating nutrient loads within the Bay (Maroon 2011; Newell and Mann 2012; NOAA Chesapeake Bay Office 2013; STAC 2013).

Oysters are such prodigious filter feeders that prior to the 1870s the entire water column could have been filtered within 3-6 days (Newell 1988). The combined effects of overfishing, habitat degradation, eutrophication, and the appearance of two diseases MSX (Haplosporidium nelson) and dermo (Perkinsus marinus) have depressed this natural oyster population by over $99 \%$ (Rothschild et al. 1994; Jackson et al. 2001; Wilberg et al. 2011), increasing the time it takes to filter the bay's water column to almost a year (Newell 1988). Oysters sequester nitrogen and phosphorus both in their shell and meat (Newell and Mann 2012). In addition, natural oyster reefs facilitate denitrification in the Bay through the deposition of feces and pseudofeces into the sediment (Newell and Mann 2012; Kellogg et al. 2013). The evidence indicates that the oyster population historically played a key role in maintaining the Bay's nitrogen cycle and water quality.

The role tradable permits can play in addressing water-borne pollution externalities is an important and complex issue, as attested by the numerous economic surveys and reviews on the topic (e.g., Letson 1992; Shortle and Horan 2001, 2008; Selman et al. 2009; Shortle 2013).

Although some research has been undertaken in the role trading can play in abating nutrient pollution from finfish aquaculture (Nielsen 2012; Nielsen, Andersen, and Bogetoft 2014), the majority of work on fisheries has focused on shellfish and their ability to filter pollutants from the water (e.g., Lindahl et al. 2005; Gren, Lindahl, and Lindqvist 2009; Grabowski et al. 2012; Pollack et al. 2013; Baker et al. 2015).

The potential economic value of the denitrification and nutrient sequestration services provided by oysters has been explored both for natural oyster reefs (Kasperski and Wieland 2010; Mykoniatis and Ready 2015) and in aquaculture operations (Miller 2009). However, these papers did not consider the constraining factor in oyster population dynamics, namely the availability of clean oyster shell for juvenile oyster spat settlement (Mann and Powell 2007; Powell and Klinck 2007). Although various artificial substrates, such as granite rocks or concrete structures, can function effectively as alternative oyster reefs (Lipcius and Burke 2006; Theuerkauf, Burke, and Lipcius 2015), they are usually not of a structural form that lends itself to harvest. Consequently, oyster shell is the preferred substrate for rehabilitating harvest grounds, because 
oysters not only settle on, grow, and survive well on oyster shell, but they are also readily culled and harvested from shell.

Oyster restoration takes many forms, involving one or more types selectively or in combination. One is the construction of oyster reef sanctuaries where harvest is prohibited. These oyster sanctuaries may be connected through larval dispersal to harvest grounds (Lipcius et al. 2008), but this is not the focus of our analysis because the data necessary to parameterize models for this alternative are not available. Another form involves construction of harvest reserves or rotational harvest grounds, whereby previously harvested grounds are rehabilitated through provision of oyster shell, either dredged from fossil deposits or purchased from shucking operations, then protected from harvest for one to a few years. These areas are subsequently harvested at a sustainable level of fishing mortality. Such is the mode of operation on harvest grounds in Louisiana, Florida, the Delaware Bay, and, historically, the Chesapeake Bay. The goal here is to achieve profitable harvest without unsustainable depletion of the shell resource; one example of this has been implemented in the Delaware Bay for years, even in the presence of persistent disease challenge using a shell-budget model (Powell et al. 2012).

Harvest thus affects the oyster's population dynamics through two channels: the direct removal of living oysters and the removal of future oyster habitat. These dynamics are particularly important when considering the issue of nutrient sequestration, because the removal of the meat and shell from the Bay is a major channel by which nutrient credits could be generated (Newell et al. 2005; Miller 2009; Mykoniatis and Ready 2015). ${ }^{2}$ In this situation, estimation of economic benefits has typically only involved fishery harvest, not those resulting from ecosystem services. Those that have addressed ecosystem services have used bioeconomic models that provide general answers (Kasperski and Wieland 2010; Mykoniatis and Ready 2015), but do not specifically deal with the habitat-related population dynamics of oysters. Further, recent research suggests that multiple oyster reef equilibria exist, and reef height determines the oyster population trajectory (Jordan-Cooley et al. 2011).

As an example of public support for oyster restoration, the oyster fishery in Maryland was highly subsidized, highlighting the public's vested interest in the topic. Public funds were used to grow juvenile "seed" oyster in aquaculture facilities, which were then transferred to natural reefs to bolster weak natural recruitment to the fishery (Maryland Department of Natural Resources 2014). To enhance natural settlement, clean oyster shell was also relocated to natural oyster reefs from either fossil beds on land or buried natural reefs (Maryland Department of Natural Resources 2014). Oyster harvest reserves were restored with oyster shell and seed, but were opened to harvest three years after seeding in what became a "put and take" fishery. The failure of those efforts to achieve lasting restoration led to the current approach of designating oyster sanctuaries, distinct areas where no oyster harvest is allowed, in addition to harvest grounds (Maryland Department of Natural Resources 2014). In other locations, such as the lower Chesapeake Bay, Louisiana, and Florida, seeding harvest grounds is unnecessary because there is sufficient recruitment of larvae onto the restoration reefs (Lipcius et al. 2015). Eventually, this may also be achieved in Maryland when there is an adequate oyster sanctuary network (North et al. 2011). Moreover, disease challenge has been dealt with successfully by allowing oyster popula-

2. The removal of nitrogen and phosphorus through oyster harvest has been vetted by the Chesapeake Bay Program, the multijurisdictional organization directing restoration and protection of the Bay, for inclusion into the Chesapeake Bay TMDL implementation plan (STAC 2013). 
tions to evolve disease resistance (Carnegie and Burreson 2011), by limiting harvest to sustainable levels based on the level of disease mortality (Powell et al. 2012), or less so recently by transplanting oysters. These restoration efforts are thus driven by the desire to reestablish the ecosystem services of oyster reefs, beyond the direct provisioning of harvested oysters.

Jordan-Cooley et al. (2011) developed a system of differential equations to capture complex population dynamics at the oyster reef scale. The three equations of the model govern the live oyster population, shell availability and reef height, and siltation rates. We couple this model to an economic value function and investigate trajectories towards steady-state equilibria at the reef scale, as opposed to focusing on steady-state dynamics themselves. There are two reasons why calculating the net present value (NPV) along the dynamic path is critical to making policy decisions in this context. ${ }^{3}$ First, the costs and benefits of the policy options are not contemporaneous in this system. Specifically, a large upfront investment must be made to restore an oyster reef, whereas benefits accrue over many subsequent years. Second, the population takes on the order of five years to approach equilibrium, post restoration. These reef-level trajectories are of great interest to fisheries managers, given the current state of the natural oyster population in the bay and the fact that restoration decisions are made at a relatively fine spatial scale. The discounted flow of rewards generated from the value function is maximized throughout the life of the reef, conditional on the initial state of the oyster reef and oyster population, using numerical dynamic programming and simulation techniques. The model specified in this article provides guidance for current harvest and restoration efforts at the most relevant spatial scale. It also helps address two fundamental questions regarding the management of restoration projects. First, does the optimal management of an oyster reef intended to achieve a given level of nutrient removal entail some harvest of oysters? Second, are the benefits from an optimally managed restored oyster reef sufficient to cover the cost of restoration?

Comparing an optimized ecosystem-based management (EBM) approach to values generated from a single stream (either harvest only, akin to traditional management regimes, or nutrient-credit value only) indicates there are substantial gains from EBM. The value generated from nutrient trading credits with no harvest generates a NPV gain of just under $\$ 2$ million. The historical approach of allowing only harvest, with no nutrient-credit value, indicates that restoration costs are unlikely to be covered by fishery returns alone. The EBM strategy allowing management to capitalize on both harvest and nutrient credits provides substantially higher values, with the core scenario generating a NPV of roughly $\$ 32$ million. The results hearken back to Smith (2007), who underscores the importance of the management institutions themselves in the ability to maximize the expected benefits that can be derived from fisheries management, in that the NPV is highly dependent on the mix of benefit streams allowed by managers.

The article progresses as follows. We introduce the theoretical model, coupling an economic value function with the reef dynamics, and review general model performance. Next we scale the analysis and results to an ongoing oyster restoration project in the Bay, providing policy guidance on the tradeoff between harvest and sequestration and denitrification services when complex life-cycle dynamics are more fully considered.

3. We thank an anonymous reviewer for the suggested text more fully explaining the importance of the approach path in this management context. 


\section{OYSTER REEF BIOECONOMIC MODEL}

We begin by specifying the transition equations governing the biological dynamics of the system. Next we identify the objective function that we look to maximize, which facilitates the understanding of biological factors entering the value function. The only departure from the biological model specified by Jordan-Cooley et al. (2011) is the incorporation of harvesting impacts. For ease of notation we drop time subscripts on both state and control variables in the model specification, acknowledging that some clarity is lost. The differential equation governing the volume of live oysters on a reef is defined as:

$$
\frac{d O}{d t}=\frac{O}{1+\exp \left(-h\left(\frac{O}{2}+B-S\right)\right)}\left(r\left(1-\frac{O}{K}\right)-\mu\right)-\left(1-\frac{1}{1+\exp \left(-h\left(\frac{O}{2}+B-S\right)\right)}\right) O \varepsilon-x
$$

In this specification, $O$ (live oyster volume), $S$ (sediment volume), and $B$ (oyster shell volume) represent the three state variables of the system, all of which are measured in cubed meters, while $t$ represents time. The unit of volume is based on a $1 \mathrm{~m}$ by $1 \mathrm{~m}$ footprint, such that the change in volume is coincidentally the change in height of live oyster, shell reef, and sediment. The instantaneous rate of population increase, $r$, oyster population carrying capacity, $K$, instantaneous mortality rate due to sedimentation burial, $\varepsilon$, mortality rate due to predation and disease, $\mu$, and scaling factor, $h$, are all specified in the model to be consistent with biological estimates and theory.

The ratio $f(O, B, S)=\frac{1}{1+\exp \left(-h\left(\frac{O}{2}+B-S\right)\right)}$ scales the population of live oysters to represent the oysters that are unaffected by sedimentation, and thus available to contribute to population growth in the next period. Buried oysters are assumed to die of suffocation at rate $\varepsilon$, with the exact impact of sedimentation modeled as a sigmoid curve in which more than $1 / 2$ a live oyster must be buried before it is affected by sedimentation. The function $f$ has the properties $f^{\prime}(\cdot)>0$, $f(0)=\frac{1}{2}, \lim _{d \rightarrow-\infty} f(d)=0$, and $\lim _{d \rightarrow \infty} f(d)=1$, and the scaling factor, $h$, governs the rate at which the proportion of oysters affected by sedimentation transitions from 0 to 1 .

The range and core value for these parameters, and all other arguments to be specified, can be found in table 1. The biological parameters are pulled directly from Jordan-Cooley et al. (2011), with the core parameterization consistent across both papers. The control variable, $x$, represents oyster harvest. Oyster population dynamics thus follow a logistic growth function, which is augmented to incorporate the impact of burial, predation and disease, and harvest.

A second differential equation, defined in equation 2 below, governs the dynamics of oyster shell availability:

$$
\frac{d B}{d t}=\frac{O \mu}{1+\exp \left(-h\left(\frac{O}{2}+B-S\right)\right)}+\left(1-\frac{1}{1+\exp \left(-h\left(\frac{O}{2}+B-S\right)\right)}\right) O \varepsilon
$$

The $\gamma$ term represents the natural rate of oyster shell decay, with all other arguments as previously specified. An important consideration built into equations 1 and 2 that warrants clarification is that only unburied oyster shell contributes positively to the population dynamics. Although mortality from both predation and disease and burial can contribute to the stock of shell, this only translates into viable oyster habitat if the volume of shell is greater than silt. 
Table 1. Model Arguments and Values

\begin{tabular}{|c|c|c|c|c|}
\hline Argument & Definition & Range & Core & Sensitivity \\
\hline $\mathrm{O}$ & Oyster volume & State & & \\
\hline B & Oyster shell & State & & \\
\hline S & Siltation rate & State & & \\
\hline $\mathrm{x}$ & Harvest & Control & & \\
\hline$\varepsilon$ & Mortality due to sediment & 0.94 & 0.94 & \\
\hline$\mu$ & Predation and disease mortality & $0.2-0.6$ & 0.4 & $0.2,0.6$ \\
\hline$\gamma$ & Oyster shell degradation rate & $0.5-0.9$ & 0.7 & $0.5,0.9$ \\
\hline $\mathrm{K}$ & Oyster carrying capacity & $0.1-0.3$ & 0.3 & $0.1,0.3$ \\
\hline $\mathrm{r}$ & Instantaneous rate of pop. increase & $0.7-1.3$ & 1 & $0.7,1.3$ \\
\hline$F_{0}$ & Maximum sediment filtration rate & 1 & 1 & \\
\hline $\mathrm{C}$ & Maximum sediment deposition rate & $0.04-0.08$ & 0.02 & 0.08 \\
\hline$y_{0}$ & Sediment value maximizing filtration & 0.02 & 0.02 & \\
\hline$\beta$ & Sediment erosion rate & $0.02-0.04$ & 0.01 & \\
\hline $\mathrm{h}$ & Scaling factor & $10-30$ & 20 & \\
\hline$\eta$ & Decay rate of sediment & 3.33 & 3.33 & \\
\hline$p_{H}$ & Harvest price $/ \mathrm{m}^{3}$ & $\$ 143.82-\$ 323.59$ & $\$ 223.91$ & $\$ 185.85, \$ 264.22$ \\
\hline$p_{N}$ & Nitrogen price/lb. & $\$ 0-\$ 20$ & $\$ 10$ & $\$ 0, \$ 4, \$ 20$ \\
\hline c & Cost $/ \mathrm{m}^{3}$ harvested & $\$ 0-\$ 195.65$ & $\$ 150.22$ & $\$ 0, \$ 65.22, \$ 195.65$ \\
\hline$\theta$ & Percent of harvest of market size & 0.67 & 0.67 & \\
\hline$\alpha$ & lbs. nitrogen sequestered $/ \mathrm{m}^{3}$ oysters & 3.47 & 3.47 & \\
\hline$\delta$ & Discount rate & $0.03-0.118$ & 0.05 & $0.03,0.07,0.118$ \\
\hline
\end{tabular}

The third transition equation for the system governs siltation, and is specified as:

$$
\frac{d S}{d t}=-\beta S+C \exp (-\eta(O+B)) \exp \left(-\frac{F_{0} O}{y_{0}} \exp \left(\frac{y_{0}-C \exp (-\eta(O+B))}{y_{0}}\right)\right)
$$

The natural sediment erosion rate, $\beta$, rate of decay for the reef due to sedimentation, $\eta$, maximum oyster filtration rate, $F_{0}$, sedimentation rate corresponding to maximum filtration, $y_{0}$, and maximum sedimentation rate, $C$, are parameters defining the local reef environment that affect both the quantity of sediment in the water column, as well as the speed at which oysters can filter the sediment out of the water. All other arguments have previously been specified. The first term of equation 3 represents the natural erosion of sediment, while the second term defines the proportion of sediment that contributes towards burial because it is not filtered from the water column by oysters.

Ultimately the manager's problem is one of selecting the harvest rate that maximizes the discounted flow of benefits derived from oysters, subject to the constraints imposed by the oyster population dynamics defined in equations $1-3$. In this article, we consider two values derived from the oyster population: the value of direct harvest for consumptive purposes and the generation of nutrient credits in order to meet TMDL regulations for the Bay. Given we are modeling a single reef within the Bay, from which a very small portion of overall oyster market supply is generated, we focus solely on harvesting profits for the consumptive benefit generated from oysters and take the market price of oysters as exogenous. Profits are specified as follows:

$$
\pi(x, O)=\left(p_{H} \theta-c\left(1-\left(\frac{O-x}{K}\right)\right)\right) x .
$$


The $p_{H}$ represents the market price for a Maryland bushel of oysters scaled to represent a cubed meter, $\theta$ is a scaling factor representing the percentage of the oyster population that is market size and captures the fact that not all oysters harvested can be sold, $c$ is the maximum cost of harvest, and all other arguments are as previously specified. The cost of harvest is modulated by the ratio of the current oyster population (minus harvest) to the carrying capacity. In this manner, costs are decreasing in the oyster population and nonlinearly increasing in harvest. The exact specification of a cost function is somewhat arbitrary given that data does not exist to estimate costs at this fine a spatial scale. However, intuitively it makes sense to have the cost of harvest dependent on the density of oysters on the reef (i.e., the lower the number of oysters on the reef, the harder it is to extract those oysters), which is what the modulation factor achieves. Although sensitivity around the choice is conducted, we set the default cost of harvest equal to $p_{H} \theta$ in order to ensure that profits are zero with complete elimination of the oyster population. The default harvest price, $p_{H}$, corresponds to a 31-year average real price of $\$ 28.90$ per MD bushel (Maryland Department of Natural Resources 2006), with the low and high values of the sensitivity analysis equal to the first and third quartile of the same data.

Oysters are assumed to generate nutrient credits separately through two channels. ${ }^{4}$ The first is denitrification, which refers to the fact that the biodeposition of filtered organic particles as either feces or pseudofeces by oysters enhances the rate of denitrification by anaerobic bacteria (Newell et al. 2005; Kellogg et al. 2013). While highly variable from location to location, this reef-level denitrification rate is quantified in a recent paper by Kellogg et al. (2013) to be as much as $61 \mathrm{~g} \mathrm{~N} \mathrm{~m}^{-2} \mathrm{y}^{-1}$ for a restored oyster reef. Given that denitrification is conditional on the biodeposition rate, we assume that the nutrient credit is proportional to the oyster filtration rate:

$$
D=\lambda\left(1-\exp \left(-\frac{F_{0} O}{y_{0}} \exp \left(\frac{y_{0}-\operatorname{Cexp}(-\eta(O+B))}{y_{0}}\right)\right)\right) .
$$

In equation $5, \lambda$ represents the denitrification rate of a restored oyster reef, and the second factor represents the filtration rate, as a percentage of the maximum filtration rate under optimal conditions; $D$ equals the rate of denitrification on the reef.

The second channel by which oysters can generate nutrient credits is sequestration, or the fact that oyster shell and meat act as nitrogen sinks, locking the nutrient away. This sequestration occurs in both the meat and shell of the oyster, and thus the generation of credits is modeled as a linear function of the growth in the oyster population:

$$
G=\alpha\left(O\left(\frac{r\left(1-\frac{O}{k}\right)+\varepsilon-\mu}{1+\exp \left(-h\left(\frac{O}{2}+B-S\right)\right)}-\varepsilon\right)\right) .
$$

In equation $6, G$ defines the rate of nitrogen sequestration by oysters, and $\alpha$ represents the $61.759 \mathrm{~g} \mathrm{~N} \mathrm{~m}^{-2}$ estimated to be sequestered in oysters from Kellogg et al. (2013), scaled to represent a cubic meter of oysters. All other arguments are as previously defined. Of note is that positive increases in extant oyster biomass are awarded nutrient credits for sequestration, regardless of whether the oysters are then harvested. This ensures that there is no double-counting

4. We focus on nitrogen dynamics for the model and subsequent analysis, which is more complicated than phosphorus removal that occurs primarily through sequestration in meat and shell. Thus, the values obtained are conservative estimates of the total nutrient removal value. 
of sequestration services, but also allows for harvested oysters to contribute to the total nutrients sequestered, given that they are removed from the system.

The full current value of the nutrient credits is:

$$
\begin{aligned}
E(O, B, S)= & p_{N}\left[\lambda\left(1-\exp \left(-\frac{F_{0} O}{y_{0}} \exp \left(\frac{y_{0}-\operatorname{Cexp}(-\eta(O+B))}{y_{0}}\right)\right)\right)\right. \\
& \left.+\alpha O\left(\frac{r\left(1-\frac{O}{k}\right)+\varepsilon-\mu}{1+\exp \left(-h\left(\frac{O}{2}+B-S\right)\right)}-\varepsilon\right)\right] .
\end{aligned}
$$

The $p_{N}$ term represents the market value of nutrient credits. As previously mentioned, although oysters are not currently eligible to generate nutrient credits, there are nutrient trading programs in the Bay watershed, although they are relatively limited in scope. We utilize the current price of credits on this market to assess the value of the nitrogen removed by oysters from Bay waters, but conduct sensitivity analysis around this price in order to assess the impact of exogenous shifts in nutrient prices on optimal extraction rates. We again assume that the price of nitrogen on the trading market is exogenous. This is appropriate given the scale of the modeling exercise. However, the assumption would need to be revisited if trading of oyster-generated nutrient credits was ultimately scaled Bay wide.

The full deterministic maximization problem is thus:

$$
\begin{aligned}
\nu(O, B, S ; x)= & \max _{x} \int_{0}^{\infty}(\pi(x, O)+E(O, B, S)) e^{-\delta t} d t \text { s.t. } \\
\frac{d O}{d t}= & O\left(\frac{r\left(1 \frac{O}{k}\right)+\varepsilon-\mu}{1+\exp \left(-h\left(\frac{O}{2}+B-S\right)\right)}-\varepsilon\right)-\theta x \\
\frac{d B}{d t}= & O\left(\frac{\mu-\varepsilon}{1+\exp \left(-h\left(\frac{O}{2}+B-S\right)\right)}+\varepsilon\right)-\gamma B \\
\frac{d S}{d t}= & -\beta S+C \exp (-\eta(O+B)) \exp \left(-\frac{F_{0} O}{y_{0}} \exp \left(\frac{y_{0}-\operatorname{Cexp}(-\eta(O+B))}{y_{0}}\right)\right) \\
& 0 \leq O \leq K ; 0 \leq B \leq 1 ; 0 \leq S \leq 0.1 .
\end{aligned}
$$

The flow of benefits in time $t$ are discounted by the rate $\delta$. Although consistent with environmental observations, the constraints on shell volume and siltation were chosen after a broader search narrowed down the relevant state space for the questions being posed. We use dynamic programming to numerically solve the Bellman Equation:

$$
\begin{aligned}
\delta V(O, B, S, t)= & \max _{x} \pi(x, O)+E(O, B, S) \\
& +\left(O\left(\frac{r\left(1-\frac{O}{k}\right)+\varepsilon-\mu}{1+\exp \left(-h\left(\frac{O}{2}+B-S\right)\right)}-\varepsilon\right)-x\right) V_{O} \\
& +\left(O\left(\frac{\mu-\varepsilon}{1+\exp \left(-h\left(\frac{O}{2}+B-S\right)\right)}+\varepsilon\right)-\gamma B\right) V_{B} \\
& +\left(-\beta S+C \exp (-\eta(O+B)) \exp \left(-\frac{F_{0} O}{y_{0}} \exp \left(\frac{y_{0}-\operatorname{Cexp}(-\eta(O+B))}{y_{0}}\right)\right)\right) V_{S} .
\end{aligned}
$$


Substituting equations 4 and 7 into 9 , the first order equation is $p_{H} \theta-c\left(1-\left(\frac{O-2 x}{K}\right)\right)=V_{O}$ which is the familiar equimarginal principle setting the marginal profit earned from harvest today equal to the marginal value of the oyster if left on the reef, in terms of future harvest potential and denitrification/sequestration services. Of note is that the harvest has no direct effect on either the sequestration or denitrification value derived from the reef, for reasons previously indicated. Instead, these values are indirectly affected by harvest through the oyster stock dynamics and impact on the future value stream. The first-order condition can be rearranged to solve for $\mathrm{x}$ :

$$
x\left(O, V_{O}\right)=\frac{k}{2 C}\left(p_{H} \theta-c+\frac{c O}{K}-V_{O}\right) .
$$

This explicit solution for $x$ can be substituted into equation 9 to form the concentrated Bellman Equation, leaving $V_{O}, V_{B}$, and $V_{S}$ to be solved numerically, given the parameter values defined in table 1. Numerical results were computed in MATLAB (MATLAB 2013) using collocation policy iteration in the CompEcon Toolbox (Miranda and Fackler 2002). The state space is approximated using a linear spline, with 90 nodes fitting $\mathrm{O}, 7$ nodes fitting B, and 4 nodes in $\mathrm{S}$ space. Convergence tolerance was set to the square root of machine precision $(\sim 1.49 \mathrm{e}-8)$.

\section{MODEL RESULTS}

Although an infinite horizon dynamic program was used to solve the optimization problem, we simulate the system dynamics to investigate the approach path to the steady state under alternative scenarios. The approach path is of keen interest to managers in understanding under what circumstances, and in which period, harvest is optimal. Further, given the state transition equations do not readily map into the harvest, denitrification, and sequestration values, simulation was used to decompose the value function into its constituent parts, but the infinite horizon value for each is calculated and reported. ${ }^{5}$

The simulations were initialized with an oyster population volume of 0.1 , a third of carrying capacity, and sediment volume of 0.01 . Shell volume is set equal to the point at which the rate of shell growth minus siltation is equal to zero $\left(\frac{d B}{d t}-\frac{d S}{d t}=0\right)$, which varies with the scenarios investigated and, as will be seen in the next section, has implications for the costs of restoration. ${ }^{6}$ The next section will also return to a discussion of the last four columns of table 2 . The results in table 2 illustrate the core specification dynamics against scenarios illustrating the range of outcomes encountered based upon parameter values within the natural variation of the system, with all dollars represented in present value. The table indicates that optimal paths and system dynamics are more sensitive to biological parameter values than market values. Four scenarios lead to extinction of the oyster population given the initial parameter values, $r=0.7, C=0.08, K=$ 0.1 , and $h=10$, all of which are biological parameter values within the natural variability

5. A 750-year time horizon was used to assess the convergence of the current value of profits generated between two time periods, with convergence defined as $\pi_{t}-\pi_{t-1} \leq$ machine precision $(\sim 1.49 \mathrm{e}-8)$. Once convergence was achieved, the steady-state present value function was integrated between the time period of convergence and infinity. The result was added to the present value of optimal management up until the point of convergence. If convergence was not achieved by period 750 , the value function was integrated between period 750 and infinity, holding state and action variables constant at their values in period 750 . The proportion of value generated from denitrification, sequestration, and harvest do not change with a shorter time horizon, such as 50 years.

6. We thank an anonymous reviewer for this suggestion. 


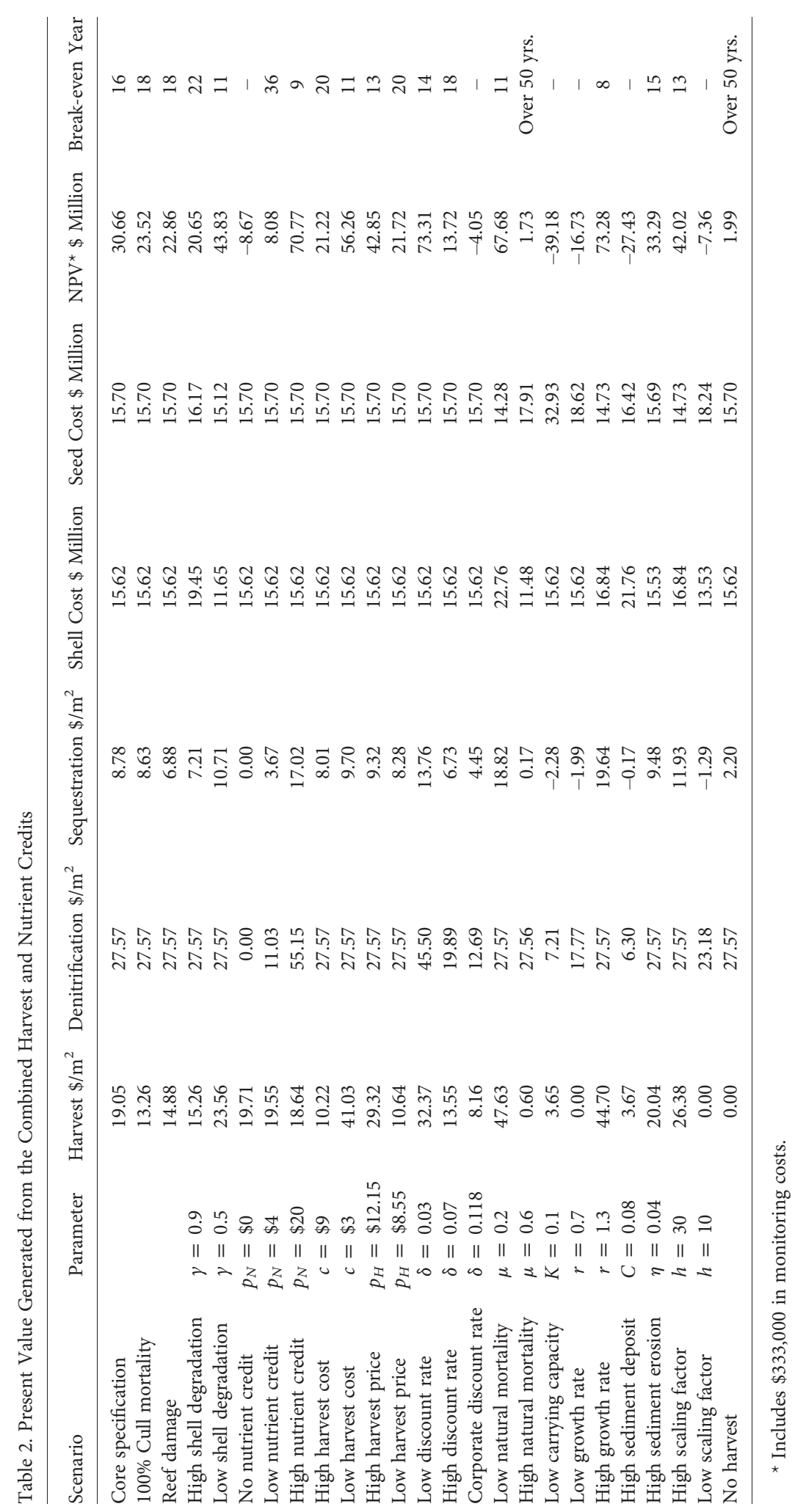

This content downloaded from 139.070.105.197 on March 23, 2020 13:14:13 PM All use subject to University of Chicago Press Terms and Conditions (http://www.journals.uchicago.edu/t-and-c). 
occurring on oyster reefs. Only two of the four scenarios leading to oyster extinction include direct harvest as an optimal strategy at any point within the time horizon modeled. This is a result of the additional in situ value associated with denitrification and represents a departure from optimal harvest of renewable resources with depensatory growth thresholds that generate only a single benefit stream (e.g., Clark, Munro, and Sumaila 2010). The result also highlights the added value of this article's reef-level tactical model, encapsulating local system dynamics for managing oyster reefs, over the existing analyses that model the entire Bay oyster population as a homogenous whole.

Predation and disease mortality, the carrying capacity, and population growth rates substantially affect system dynamics across all dimensions. The population density in the terminal year of the simulation varies from a low of extinction to a high of roughly 580 oysters $\mathrm{m}^{-2}$, with a core parameterization level of 443 individuals $\mathrm{m}^{-2}$ and average of 372 oysters $\mathrm{m}^{-2}$. These levels are substantial, given that densities on public reefs rarely exceed 100 oysters $\mathrm{m}^{-2}$ (Schulte, Burke, and Lipcius 2009).

Beyond sensitivity to different harvest and nutrient credit prices, we also investigate different assumptions of gear impacts on population dynamics in two different manners. First, the core parameterization assumes that sub-market sized oysters that are culled and returned to the water face no increased mortality due to handling; thus, nutrient sequestration and productivity due to these oysters is not lost. Although there is little evidence of increased mortality due to the culling process, the sensitivity of our results to this assumption was tested by assuming a $100 \%$ mortality rate of culled oysters under market size. The results are relatively robust to this assumption, with negligible change in optimal live oysters on the reef, although harvest itself decreases by an annual average of $34 \%$, and annual profits decrease $11 \%$.

Second, the core parameterization assumes that there is no impact of harvest on shell availability beyond the harvest of live oysters themselves. In fact, the act of harvest itself can have an impact on reef height and oyster shell availability (Lenihan and Peterson 2004), although this finding is not consistent throughout the literature (Powell et al. 2001) and differs by harvest technology. In order to assess the impact of additional damage to the reef structure, we assumed that the volume of live oysters harvested corresponds to a commensurate removal of oyster shell at a 1:1 ratio. This assumption, again, leads to negligible changes in optimal volume of live oysters on the reef, though annual harvest drops by $26 \%$ and total annual profits are reduced by an average of $12 \%$.

\section{HARRIS CREEK RESTORATION}

We demonstrate the utility of our approach by applying it at a scale equivalent to an actual oyster reef restoration project currently being conducted in Harris Creek, located near the mouth of the Choptank River on the eastern shore of Maryland (figure 1). The project plan calls for 153 hectares of restored oyster reef; requiring the placement of over 267,594 cubic meters of substrate and the planting of over 2 billion oyster seed (seed = juvenile oysters; Maryland Department of Natural Resources 2014). The reef is expected to take six years to achieve full functionality. The total project cost is estimated to be over US\$31.65 million and will rely entirely on public funding through both federal and state dollars. Of this total, $\$ 15.698$ million is dedicated to purchasing and planting seed, while $\$ 15.62$ million is reserved for transplanting shell to the reef, and $\$ 0.333$ million is for monitoring of the restoration progress. 


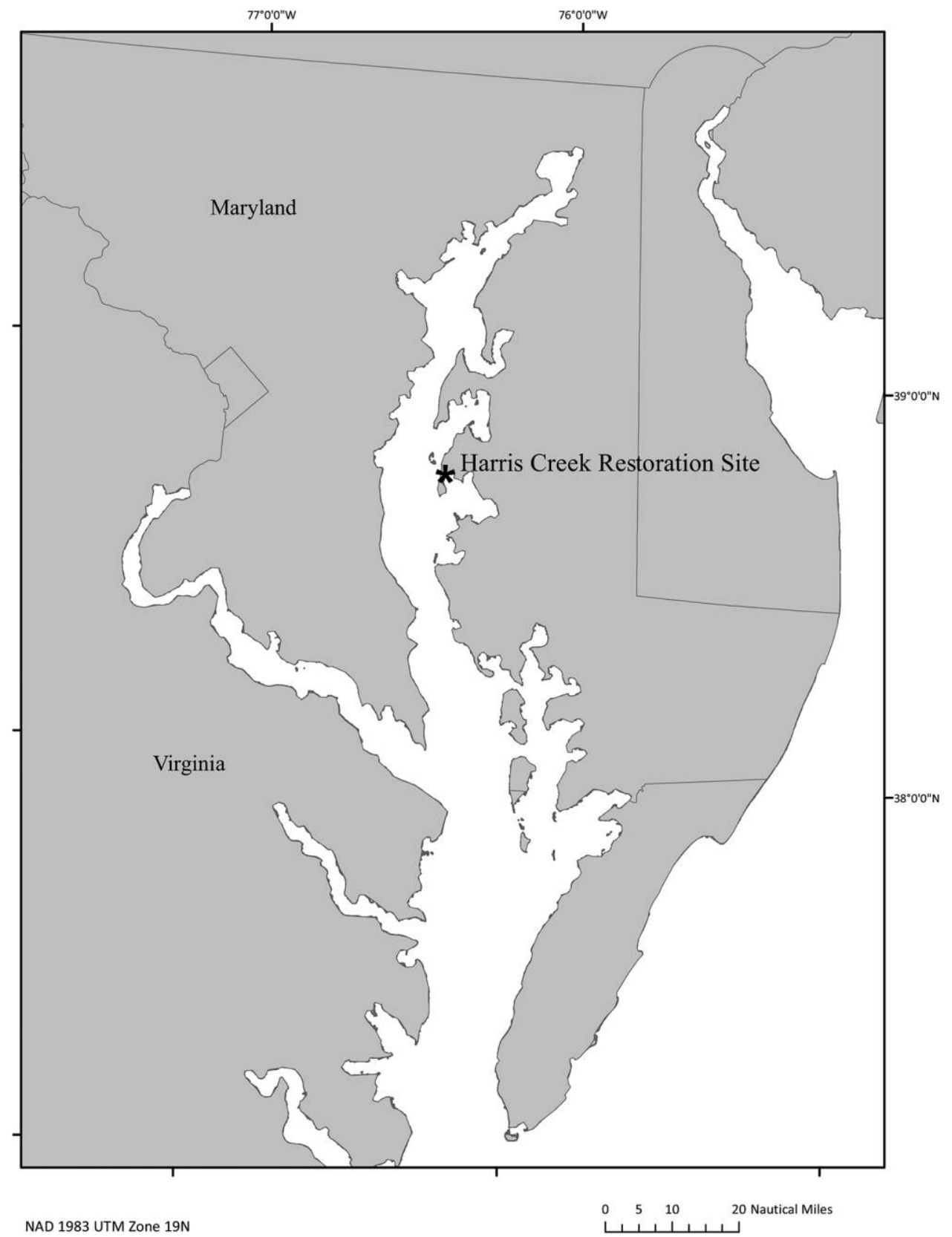

Figure 1. Harris Creek Restoration Site

From the perspective of justifying government expenditures, we are interested in the NPV of a similarly sized reef restoration project. Using the outcomes from the model simulations in the previous section, we calculate the infinite horizon NPV of oyster reef ecosystem services for each model run using the assumption that all project costs are incurred in the initial year. Due to budget constraints the actual restoration in Harris Creek is being phased in over several years, indi- 
cating our estimates are conservative estimates of the net benefits that can be achieved. We assume that in year six our hypothetical reef is restored and will begin performing based on the modeling and simulation results in the previous section. Although the reef will generate some ecosystem service benefits during the period from initial planting to restoration, our simulations are not designed to capture this period. Therefore, our estimates of ecosystem service benefits are again on the conservative side of the total value generated, as indicated by other restoration projects where reef functionality was achieved after three years (Schulte, Burke, and Lipcius 2009; Lipcius et al. 2015). These assumptions may reflect a realistic approach to establishment of best management practices, in that the sale of nutrient credits would most likely not be allowed until a functioning, sustainable oyster reef were to be credibly established. Another major difference from the actual Harris Creek restoration is that it is designated as strictly an oyster sanctuary, so that no oyster harvest will be permitted. Among other things, we are interested in examining the impact of the no harvest policy on the value generated of a similar reef, were it to be established.

Given that some scenarios have different implications for restoration costs, we scale the costs relative to the core parameterization as follows. The cost of seed is assumed to be proportional to the ratio of oyster volume, in time period 2 and setting $x=0$, between the core parameterization and scenario of interest. Period 2 is used due to the oyster population being equal across scenarios in period 1 by design. Identifying the magnitude and direction of the population change between periods 1 and 2 identifies the relative location of each scenario along the logistic function defined in equation 1, which provides an estimate of the relative difficulty of reaching the initial oyster population volume of 0.1 . For example, shifting the carrying capacity from the core parameterization of 0.3 to 0.1 (the lower bound estimated for oysters in the biological literature and the starting value for the simulations) would be expected to result in substantially higher seed oyster costs, all else being equal, due to a decreasing marginal productivity of the stock as the population approaches carrying capacity. Similarly, the cost of shell is assumed proportional to the ratio of shell volume between the core parameterization and scenario of interest in period 1 . As previously stated, the starting shell volume is the solution to $\frac{d B}{d t}-\frac{d S}{d t}=0$, which will depend on the biological dynamics of the system. The ratio of starting shell volumes thus identifies the relative amount of shell that would need to be deposited during the restoration process and, by extension, the associated cost.

Our core scenario calls for oyster harvest, and results in a NPV of $\$ 30.66$ million. Of this, 50\% of the benefits are due to denitrification, $16 \%$ from nitrogen sequestration, and $34 \%$ from oyster harvest (table 2). If the sale of nutrient credits is not allowed, but harvesting is permitted, the $\mathrm{NPV}$ of the oyster reef is $-\$ 8.67$ million. If the sale of nutrient credits is allowed, but no harvest is permitted from the reef, the NPV is $\$ 1.99$ million. Interestingly, while the core scenario with harvest has the same denitrification benefits as the no harvest option, the benefits from nitrogen sequestration are almost four times greater when harvest is allowed. Harvest thus enhances the ecosystem services provided by the oyster population by equilibrating the system at a higher population growth rate.

The question has been raised as to whether private investment can either fully or partially fund restoration projects similar in scale to the Harris Creek restoration. In order to better approximate the returns necessary for private investment into a risky enterprise, we investigate the possibility of private investment by setting the discount rate equal to the 52-week maximum return for CCC rated corporate bonds. The negative NPV associated with this corporate discount rate 
(11.8\%) scenario indicates that this is an unlikely source of funding for such an undertaking. The upfront costs, delayed payoffs, and risky nature of the investment makes public funding a more realistic alternative for oyster reef restoration.

Overall, $77 \%$ of the modeled scenarios generate positive NPV, with an average benefit of $\$ 25.38$ million generated. Of those scenarios generating a positive return, the average (median) number of years after restoration in which the project breaks even is 17.6 (15). This analysis reinforces the fact that local conditions play an important role in the net benefits generated from oyster reef restoration.

Although the system dynamics are not overly sensitive to the economic parameters, the ultimate values generated from optimal management are. This is an important finding from the standpoint of maximizing the benefits to society, and indicates the key role both future price dynamics and the funding sources (encapsulated in the discount rate) would play in the NPV of restoration projects. For example, when compared to the core specification an $18 \%$ percent increase and $17 \%$ decrease in the market price of oysters translates into a $40 \%$ increase and $29 \%$ decrease in NPV. Results, in terms of NPV, are similarly sensitive to the price of nutrient credits, harvesting costs, and discount rate.

Three general regimes are of most importance to managers: optimization of both harvest and credits (moving forward referred to the unrestricted model), optimization of harvest with no nutrient credits, and the value of nutrient credits generated from a sanctuary reef without harvest. Further, although uncertain, the $\$ 10$ per $\mathrm{lb}$. of nitrogen is likely much higher than what can be expected on a mature market for nutrient credits (Hanson and McConnell 2008). In order to more fully investigate the tradeoffs between these three regimes, we compare their NPV across the range of nitrogen credit and harvest prices identified in table 1. Figure 2 presents a plot of NPV from the unrestricted model against prices. The shaded region identifies price combina-

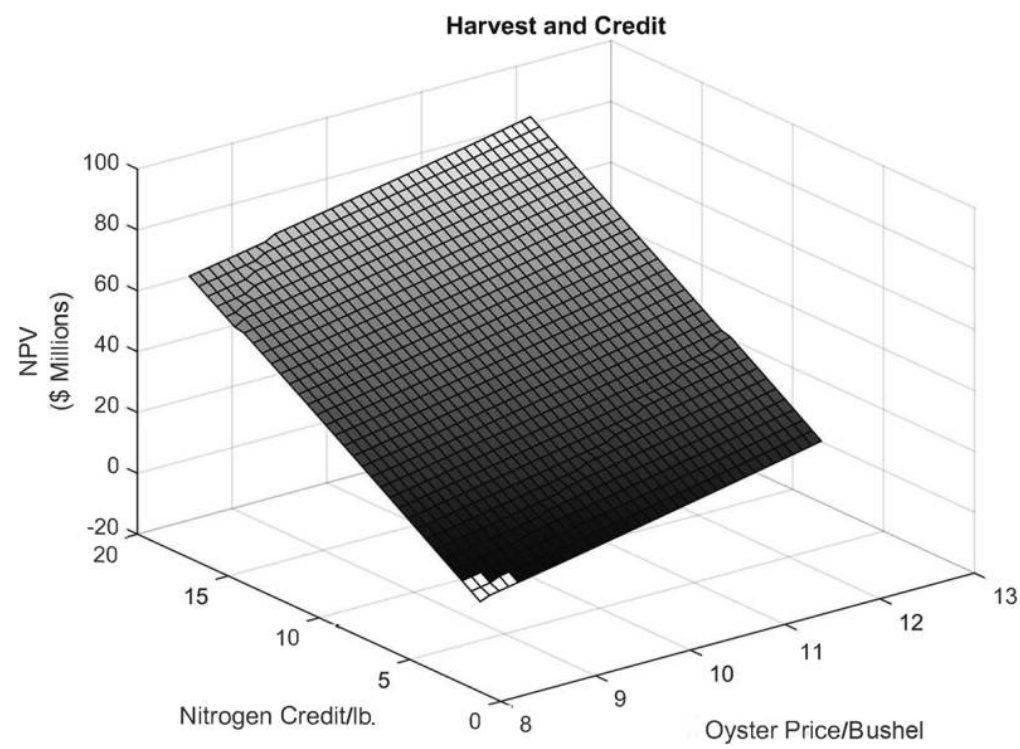

Figure 2. NPV from Harvest and Nutrient Credits across a Range of Prices (unshaded region represents negative NPV) 
tions generating a positive NPV, while the unshaded region identifies negative NPVs, for ease of visual reference. Only at the very lowest prices does the dual benefit stream fail to generate positive NPV. Of particular interest is the finding that the NPV for the unrestricted model is a concave combination of the no credit and no harvest regimes across all prices investigated. The implication is that a restored reef managed for multiple ecosystem service benefits is preferred to two individual reefs of the same combined size, with each managed for a single stream of benefits (either harvest or nitrogen credits), respectively. Even at the relatively unrealistic high nitrogen credit of $\$ 20$, some harvest is optimal. Of note is that the harvest-only scenario generates a positive NPV only for oyster prices over $\$ 11.95$, which is just under the $75^{\text {th }}$ percentile of the historical price distribution for oysters in the Bay. Conversely, nutrient credits alone generate a positive NPV at any nitrogen price above $\$ 9.50 / \mathrm{lb}$.

Figures 3 and 4 graph the difference in live oysters at equilibrium between the unrestricted model and harvest-only and nutrient-credit only scenarios, respectively, as a percentage of the unrestricted model oyster volume. Note that the axis on both figures has been rotated for a better view of the surface. The equilibrium states are interesting, in that the unrestricted model is more similar to the harvest-only scenario (maximum difference of $~ 7 \%$ ) than the credit-only scenario (maximum difference of $\sim 40 \%$ ). Given that the opposite is true for the NPV (see table 2), this disparity suggests that nutrient credits are generating a substantial portion of NPV across all price points. As previously discussed, harvesting increases the rate of sequestration. Optimal management when harvest is allowed thus equilibrates at a lower population level (most similar to the harvest-only scenario, as illustrated in figure 3), but higher population growth rate. This higher growth rate enhances the generation of nutrient credits well beyond what is achieved when only nutrient credits are generated only from the reef. Percentage differences in shell volumes are very similar in shape and magnitude to oyster volume, and thus are not presented for

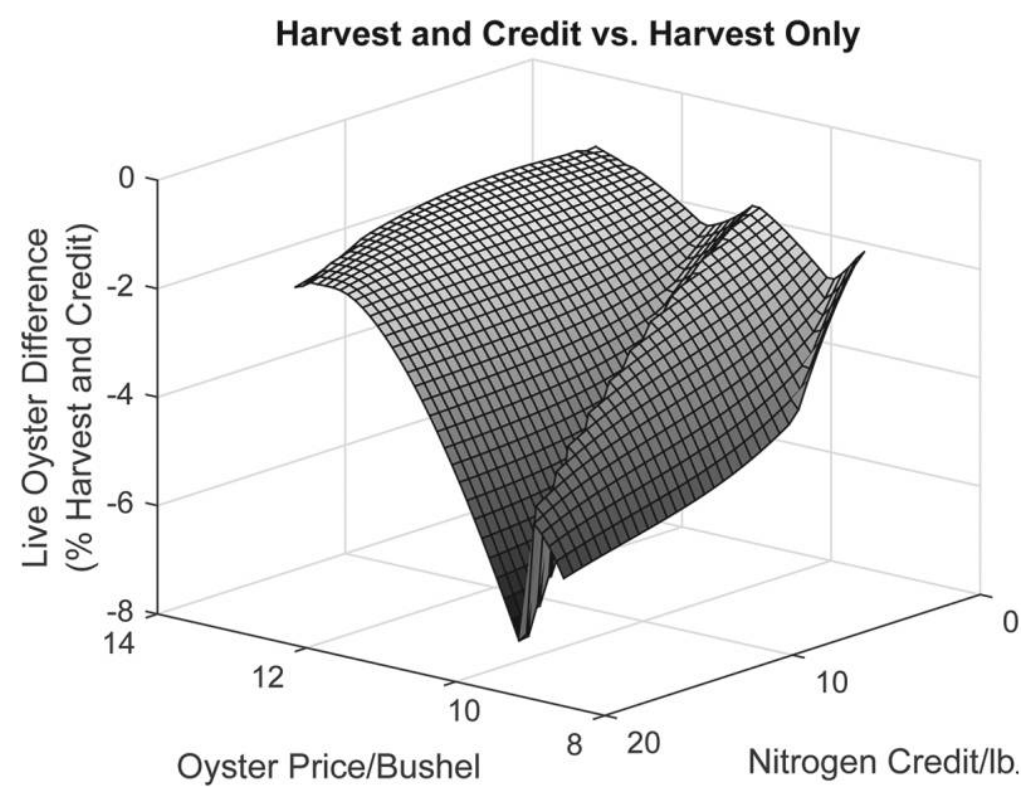

Figure 3. Difference in Live Oyster Volume between Harvest and Nutrient Credits and Harvest Alone as a Percentage of the Harvest and Credit Volume 


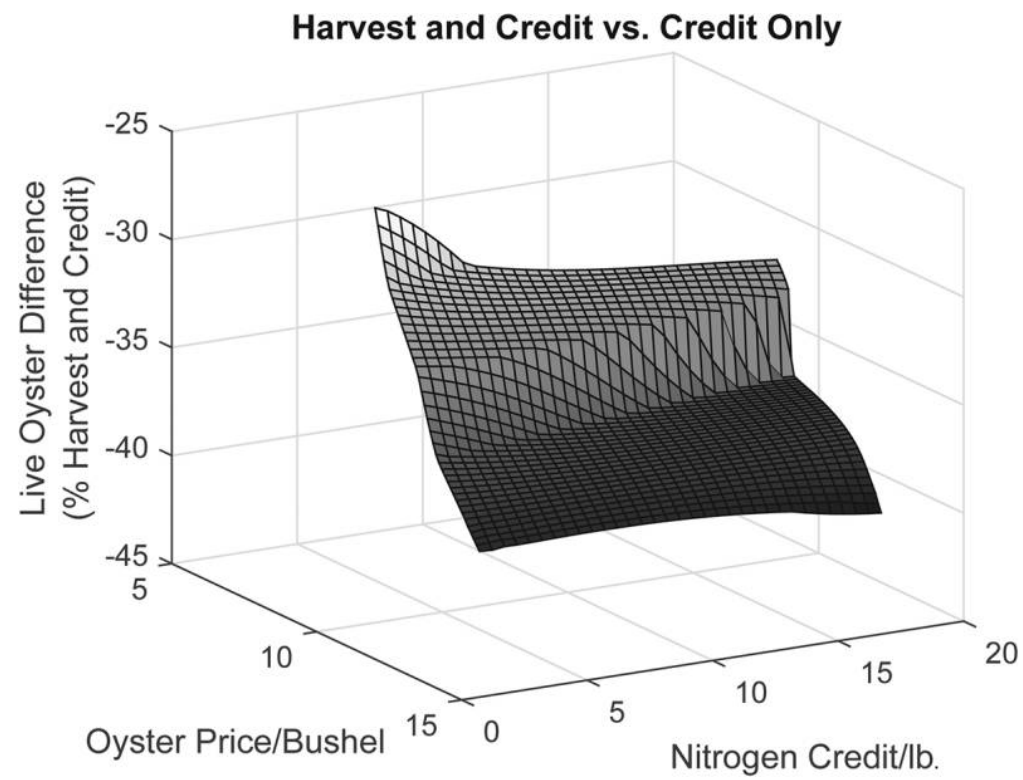

Figure 4. Difference in Live Oyster Volume between Harvest and Nutrient Credits and Credits Alone as a Percentage of the Harvest and Credit Volume

brevity. The difference in siltation rate is negligible in magnitude, with siltation rates equilibrating very near zero across all three scenarios.

\section{DISCUSSION}

By adding an economic component to an existing dynamic model of oyster reef growth, we have developed a tool that could be used to guide management of oyster reef restoration at the scale at which it is actually occurring in Bay. With additional research, the model parameters can be adjusted to reflect local conditions and help guide restoration to optimal locations. Our analysis shows that under most conditions, optimal reef management includes some amount of harvesting. This achieves higher nitrogen sequestration levels compared with what would occur if the reef were allowed to reach an unharvested equilibrium state.

The core parameterization results rely on the assumption that harvesting is relatively noninvasive, with no impact on the reef beyond oyster mortality. In reality, harvesting technologies have a differential impact on reef integrity (Lenihan and Peterson 1998), population dynamics, and maximum sustainable yield (Ducharme-Barth et al. forthcoming), and the result might also be sensitive to location and reef type (Powell et al. 2001, 2012). For instance, harvest by dredges is much more destructive than harvest by hand, hand tongs, or patent tongs (Lenihan and Peterson 1998), such that the benefits of harvest are likely to be different across these technologies. Although sensitivity analysis suggests that harvesting-induced degradation of reef integrity affects optimal harvest levels, and the NPV associated with a reef, the impact on optimal live oyster volumes on the reef is not substantial given our assumptions. Nevertheless, these differential impacts should be further explored when assessing the full impact of harvest (see Ryan, Holland, and Herrera 2014).

Our results indicate that government-funded oyster reef restoration could be financed through the issuance of bonds to be repaid with income generated by the reef. Private funding, 
however, is not likely to be viable given the high upfront costs of restoration and delayed generation of harvest and credits. Note that we use a one-to-one trading ratio, which is often not the case when awarding credits for best management practices due to the uncertainty inherent in their performance. A higher trading ratio would require adjusting the results accordingly.

Despite concerns regarding institutional constraints to incorporating ecosystem services in resource management (Scarlett and Boyd 2015), the Chesapeake Bay Program is well-organized to consider implementation of a nutrient trading program that might aid oyster restoration goals. An oyster best management practice expert working group has been created under the Chesapeake Bay Program's Water Quality Goal Implementation Team. The work of that group is being coordinated by the Oyster Recovery Partnership, a non-profit that has supported oyster restoration efforts in the Bay. Thus, the link has been made institutionally between the groups principally charged with restoring oysters and the group charged with the related ecosystem service of regulating water quality.

We do not include other ecosystem services that oyster reefs provide, which if quantified and monetized, could further justify the public subsidy. For example, we did not include phosphorus sequestration in our analysis, nor did we include the value of increased secondary production of commercially important species in the Bay (Grabowski et al. 2012). Oyster reefs also aggregate recreationally important species, which results in higher net values to recreational fishermen (Hicks, Haab, and Lipton 2004), and they control erosion (Meyer, Townsend, and Thayer 1997; Henderson and O'Neil 2003; Grabowski et al. 2012), neither of which have been accounted for in our analysis. Finally, the model assumes that nutrient sequestration occurs only in the bodies of living oysters on the reef. In reality, at least a portion of these nutrients remain sequestered in the bodies of scavengers and oyster predators; thus, our estimates of these services are conservative.

Nevertheless, denitrification and nutrient sequestration services are clearly an important consideration in optimal oyster reef management. Even this partial quantification of ecosystem services indicates that oysters have historically been managed inefficiently. Further, models encapsulating environmental dynamics at the reef level can be very useful in assessing the benefits associated with reef restoration and management regimes.

\section{REFERENCES}

Baker, S., K. Grogan, S. Larkin, and L. Sturmer. 2015. "Green Clams: Estimating the Value of Environmental Benefits (Ecosystem Services) Generated by the Hard Clam Aquaculture Industry in Florida." University of Florida IFAS Project Report, Cedar Key, FL.

Birch, M. B. L., B. M. Gramig, W. R. Moomaw, O. C. Doering, III, and C. J. Reeling. 2011. "Why Metrics Matter: Evaluating Policy Choices for Reactive Nitrogen in the Chesapeake Bay Watershed.” Environmental Science \& Technology 45(1):168-74.

Boesch, D. F., R. B. Brinsfield, and R. E. Magnien. 2001. "Chesapeake Bay Eutrophication: Scientific Understanding, Ecosystem Restoration, and Challenges for Agriculture." Lournal of Environmental Quality 30 (2):303-20.

Branosky, E., C. Jones, and M. Selman. 2011. "Comparison Tables of State Nutrient Trading Programs in the Chesapeake Bay Watershed.” World Resources Institute, Washington, DC.

Brown, L. A., J. N. Furlong, K. M. Brown, and M. K. La Peyre. 2014. "Oyster Reef Restoration in the Northern Gulf of Mexico: Effect of Artificial Substrate and Age on Nekton and Benthic Macroinvertebrate Assemblage Use." Restoration Ecology 22:214-22. 
Carnegie, R. B., and E. M. Burreson. 2011. "Declining Impact of an Introduced Pathogen: Haplosporidium nelsoni in the Oyster Crassostrea virginica in Chesapeake Bay." Marine Ecologv Progress Series 432:1-15.

Chesapeake Bay Program. 2014a. "Chesapeake Bay Watershed Agreement." http://www.chesapeakebay.net /chesapeakebaywatershedagreement/page.

_.2014b. “Trading and Offsets Workgroup.” http://www.chesapeakebay.net/groups/group/trading_and _offsets_workgroup.

Clark, C. W., G. R. Munro, and U. R. Sumaila. 2010. "Limits to the Privatization of Fishery Resources." Land Economics 86(2):209-18.

Ducharme-Barth, N., R. N. Lipcius, L. B. Shaw, and J. Shi. Forthcoming. "Reef Degradation Due to Exploitation Triggers Population Collapse and Lowers MSY in Oyster Populations." Ecological Applications.

Environmental Protection Agency. 2011. "Clean Water Act Section 303(d): Notice for the Establishment of the Total Maximum Daily Load (TMDL) for the Chesapeake Bay.” Federal Register 76(3), January 5, 2011:549-50.

Grabowski, J. H., R. D. Brumbaugh, R. F. Conrad, A. G. Keeler, J. J. Opaluch, C. H. Peterson, M. F. Piehler, S. P. Powers, and A. R. Smyth. 2012. "Economic Valuation of Ecosystem Services Provided by Oyster Reefs." BioScience 62(10):900-09.

Gren, I., O. Lindahl, and M. Lindqvist. 2009. "Values of Mussel Farming for Combating Eutrophication: An Application to the Baltic Sea." Ecological Engineering 35:935-45.

Hagy, J. D., W. R. Boynton, C. W. Keefe, and K. V. Wood. 2004. "Hypoxia in Chesapeake Bay, 1950-2001: Long-term Change in Relation to Nutrient Loading and River Flow.” Estuaries 27(4):634-58.

Hanson, J. C., and K. E. McConnell. 2008. "Simulated Trading for Maryland's Nitrogen Loadings in the Chesapeake Bay.” Agricultural and Resource Economics Review 37(2):211-26.

Henderson, J., and J. O’Neil. 2003. "Economic Values Associated with Construction of Oyster Reefs by the Corps of Engineers.” EMRRP Technical Notes Collection (ERDC TN-EMRRP-ER-01). Vicksburg, MS: U.S. Army Engineer Research and Development Center.

Hicks, R. L., T. C. Haab, and D. Lipton. 2004. "The Economic Benefits of Oyster Reef Restoration in the Chesapeake Bay." Final Report Prepared for the Chesapeake Bay Foundation, Annapolis, MD.

Jackson, J. B. C., M. X. Kirby, W. H. Berger, K. A. Bjorndal, L. W. Botsford, B. J. Bourque, R. H. Bradbury, R. Cooke, J. Erlandson, J. A. Estes, T. P. Hughes, S. Kidwell, C. B. Lange, H. S. Lenihan, J. M. Pandolfi, C. H. Peterson, R. S. Steneck, M. J. Tegner, and R. R. Warner. 2001. "Historical Overfishing and the Recent Collapse of Coastal Ecosystems." Science 293(5530):629-38.

Jones, C. G., J. H. Lawton, and M. Shachak. 1994. "Organisms as Ecosystem Engineers.” Oikos 69(3):373-86. Jordan-Cooley, W. C., R. N. Lipcius, L. B. Shaw, J. Shen, and J. Shi. 2011. "Bistability in a Differential Equation Model of Oyster Reef Height and Sediment Accumulation.” Iournal of Theoretical Biology 289:1-11.

Kasperski, S., and R. Wieland. 2010. "When is it Optimal to Delay Harvesting? The Role of Ecological Services in the Northern Chesapeake Bay Oyster Fishery." Marine Resource Economics 24(4):361-85.

Kellogg, M. L., J. C. Cornwell, M. S. Owens, and K. T. Paynter. 2013. "Denitrification and Nutrient Assimilation on a Restored Oyster Reef." Marine Ecology Progress Series 480:1-19.

Lenihan, H. S., and C. H. Peterson. 1998. "How Habitat Degradation Through Fishery Disturbance Enhances Impacts of Hypoxia on Oyster Reefs." Ecological Applications 8(1):128-40.

- 2004. "Conserving Oyster Reef Habitat by Switching from Dredging and Tonging to Diver HandHarvesting.” Fishery Bulletin 102:298-305.

Letson, D. 1992. "Point/Nonpoint Source Pollution Reduction Trading: An Interpretive Survey." Natural Resources Journal 32:219-32.

Lindahl, O., R. Hart, B. Hernroth, S. Kollberg, L. Loo, L. Olrog, A. Rehnstam-Holm, J. Svensson, S. Svensson, and U. Syversen. 2005. "Improving Marine Water Quality by Mussel Farming: A Profitable Solution for Swedish Society.” AMBIO: A Journal of the Human Environment 34(2):131-38.

Lipcius, R. N., and R. P. Burke. 2006. "Abundance, Biomass and Size Structure of Eastern Oyster and Hooked Mussel on a Modular Artificial Reef in the Rappahannock River, Chesapeake Bay.” Special Re- 
port in Applied Marine Science and Ocean Engineering No. 390, Virginia Institute of Marine Science, College of William \& Mary, Gloucester Point, VA.

Lipcius, R. N., R. P. Burke, D. N. McCulloch, S. J. Schreiber, D. M. Schulte, R. D. Seitz, and J. Shen. 2015. "Overcoming Restoration Paradigms: Value of the Historical Record and Metapopulation Dynamics in Native Oyster Restoration.” Frontiers in Marine Science 2:65.

Lipcius, R. N., D. B. Eggleston, S. J. Schreiber, R. D. Seitz, J. Shen, M. Sisson, W. T. Stockhausen, and H. V. Wang. 2008. "Importance of Metapopulation Connectivity to Restocking and Restoration of Marine Species." Reviews in Fishery Science 16(1-3):101-10.

Luckenbach, M. W., R. Mann, and J. A. Wesson. 1995. "Oyster Reef Habitat Restoration: A Synopsis and Synthesis of Approaches.” http://web.vims.edu/vimsnews/OysHabResFlyer.pdf.

Magnien, R. E. 2001. “The Dynamics of Science, Perception, and Policy During the Outbreak of Pfisteria in the Chesapeake Bay.” BioScience 51(10):843-52.

Mann, R., and E. N. Powell. 2007. "Why Oyster Restoration Goals in the Chesapeake Bay are not and Probably Cannot be Achieved." Iournal of Shellfish Research 26(4):905-17.

Markit Financial Information Services. 2016. "Pennvest Nutrient Credit Trading Program." http://www.markit.com/Product/Pennvest.

Maroon, J. H. 2011. “Emerging Issues in Nutrient Credit Trading in the Chesapeake Bay Watershed.” Report to the Keith Campbell Foundation by Maroon Consulting LLC, Midlothian, VA.

Maryland Department of Natural Resources. 2006. "Maryland Oyster Harvest: Bushels, Value, Effort 19752006.” http://www.dnr.state.md.us/dnrnews/infocus/032706hvalue.pdf.

_. 2014. "Shellfish Program: Ecological Restoration." http://dnr2.maryland.gov/fisheries/Documents /Harris_Creek_tributary_plan_011513.pdf.

MATLAB. 2013. Version R2013a. The MathWorks Inc. Natick, MA.

Meyer, D. L., E. C. Townsend, and G. W. Thayer. 1997. "Stabilization and Erosion Control Value of Oyster Cultch for Intertidal Marsh.” Restoration Ecology 5(1):93-9.

Miller, A. L. 2009. "An Economic Evaluation of the Nutrient Assimilation Potential for Commercial Oyster Aquaculture in the Chesapeake Bay.” MS thesis, Department of Agriculture and Applied Economics, Virginia Polytechnic Institute and State University.

Miranda, M. J., and P. L. Fackler. 2002. ComEcon Toolbox for MATLAB to accompany Applied Computational Economics and Finance. http://www4.ncsu.edu/ pfackler/compecon/toolbox.html.

Mykoniatis, N., and R. Ready. 2015. "Spatial Harvest Regimes for a Sedentary Fishery." Environmental and Resource Economics: 1-31 DOI 10.1007/s10640-015-9904-2.

Newell, R. I. E. 1988. "Ecological Changes in Chesapeake Bay: Are They the Result of Overharvesting the American Oyster, Crassostrea virginica?" Understanding the Estuary: Advances in Chesapeake Bay Research. Proceedings of a Conference, March 29-31 1988, Chesapeake Research Consortium Publication 129, Baltimore, MD.

Newell, R. I. E., T. R. Fisher, R. R. Holyoke, and J. C. Cornwell. 2005. "Influence of Eastern Oysters on Nitrogen and Phosphorus Regeneration in Chesapeake Bay, USA." In The Comparative Roles of Suspension Feeders in Ecosystems, ed. R. Dame and S. Olenin, Vol. 47, NATO Science Series: IV_Earth and Environmental Sciences. Netherlands: Springer.

Newell, R. I. E., and R. E. Mann. 2012. "Shellfish Aquaculture: Ecosystem Effects, Benthic-pelagic Coupling and Potential for Nutrient Trading." Report for the Secretary of Natural Resources, Commonwealth of Virginia, Richmond, VA.

Nielsen, R. 2012. "Introducing Individual Transferable Quotas on Nitrogen in Danish Fresh Water Aquaculture: Production and Profitability Gains.” Ecological Economics 75:83-90.

Nielsen, R., J. L. Andersen, and P. Bogetoft. 2014. "Dynamic Reallocation of Marketable Nitrogen Emission Permits in Danish Freshwater Aquaculture." Marine Resource Economics 29(3):219-39.

NOAA (National Oceanic and Atmospheric Administration) Chesapeake Bay Office. 2013. "Nitrogen Removal by Oysters." January 10-11, 2013, Wachapreague, VA. 
North, E. W., D. M. King, J. Xu, R. R. Hood, R. I. E. Newell, K. Paynter, M. L. Kellogg, M. K. Liddel, and D. F. Boesch. 2011. "Linking Optimization and Ecological Models in a Decision Support Tool for Oyster Restoration and Management.” Ecological Applications 20(3):851-66.

Pollack, J. B., D. Yoskowitz, H. Kim, and P. A. Montagna. 2013. "Role and Value of Nitrogen Regulation Provided by Oysters (Crassostrea virginica) in the Mission-Aransas Estuary, Texas, USA." PLOS ONE 8(6):1-8.

Powell, E. N., K. A. Ashton-Alcox, S. E. Banta, and A. J. Bonner. 2001. "Impact of Repeated Dredging on a Delaware Bay Oyster Reef.” Journal of Shellfish Research 20(3):961-75.

Powell, E. N., and J. M. Klinck. 2007. “Is Oyster Shell a Sustainable Estuarine Resource?" Journal of Shellfish Research 26(1):181-94.

Powell, E. N., J. M. Klinck, K. Ashton-Alcox, E. E. Hofmann, and J. Morson. 2012. "The Rise and Fall of Crassostrea virginica Oyster Reefs: The Role of Disease and Fishing in their Demise and a Vignette on their Management." Lournal of Marine Research 70(2-3):505-58.

Rothschild, B. J., J. S. Ault, P. Goulletquer, and M. Heral. 1994. "Decline of the Chesapeake Bay Oyster Population: A Century of Habitat Destruction and Overfishing." Marine Ecology Progress Series 111 (1-2):29-39.

Ryan, R. W., D. S. Holland, and G. E. Herrera. 2014. "Ecosystem Externalities in Fisheries." Marine Resource Economics 29(1):39-53.

Scarlett, L., and J. Boyd. 2015. "Ecosystem Services and Resource Management: Institutional Issues, Challenges, and Opportunities in the Public Sector." Ecological Economics 115:3-10.

Schulte, D. M., R. P. Burke, and R. N. Lipcius. 2009. "Unprecedented Restoration of a Native Oyster Metapopulation.” Science 325(5944):1124-28.

Selman, M., S. Greenhalgh, E. Branosky, C. Jones, and J. Guiling. 2009. "Water Quality Trading Programs: An International Overview." World Resources Institute Issue Brief, Washington, DC.

Shortle, J. 2013. "Economics and Environmental Markets: Lessons from Water Quality Trading.” Agricultural and Resource Economics Review 42(1):57-74.

Shortle, J., and R. D. Horan. 2001. “The Economics of Nonpoint Pollution Control." Lournal of Economic Surveys 15(3):255-89.

- 2008. "The Economics of Water Quality Trading." International Review of Environmental and Resource Economics 2(2):101-33.

Smith, M. D. 2007. "Generating Value in Habitat-Dependent Fisheries: The Importance of Fishery Management Institutions." Land Economics 83(1):59-73.

STAC (Chesapeake Bay Program Scientific and Technical Advisory Committee). 2013. "Evaluation of the Use of Shellfish as a Method of Nutrient Reduction in the Chesapeake Bay." STAC Publ. \#13-005, Edgewater, MD.

Theuerkauf, S. J., R. P. Burke, and R. N. Lipcius. 2015. "Settlement, Growth and Survival of Eastern Oysters on Alternative Reef Substrates." Iournal of Shellfish Research 34(2):241-50.

Virginia Department of Environmental Quality. 2016. "VPDES Watershed General Permit for Nutrient Discharges to the Chesapeake Bay." http://www.deq.virginia.gov/Programs/Water/PermittingCompliance /PollutionDischargeElimination/NutrientTrading.aspx.

Wilberg, M. J., M. E. Livings, J. S. Barkman, B. T. Morris, and J. M. Robinson. 2011. “Overfishing, Disease, Habitat Loss, and Potential Extirpation of Oysters in Upper Chesapeake Bay." Marine Ecology Progress Series $436: 131-44$. 